\title{
Gauging Affective Environmental Sustainability Attributes for Calibrating Green Consumer Behaviour among Students: A Consumer Focused Approach to Sustainability in Higher Education
}

\author{
M. N. Mohamedunni Alias Musthafa ${ }^{1}$ and K. M. Sajila ${ }^{2}$ \\ ${ }^{1}$ Associate Professor, Department of Education, Central University of Kerala, Kasaragod, Kerala, India \\ ${ }^{2} \mathrm{Ph}$. D. in Education, Department of Education, University of Calicut, Kerala, India \\ E-Mail: sajilakm500@gmail.com
}

\begin{abstract}
Multifaceted solutions have been identified in several fields and sectors for confronting the sustainability issues. The integration of sustainability in Higher Education (HE) has always aimed at creating dynamic responsible citizens capacitated to analyse, develop and act with high degree of autonomy and determination for addressing the issues of sustainability. In a purely consumerist state like Kerala, a southernmost state in India, education for green consumerism can be considered as one of the important panacea for addressing environmental sustainability issues. Therefore, this paper intends to examine how far the Affective Environmental Sustainability Attributes (Attitudes, Values and Dispositions) have influenced in adopting sustainable lifestyles among undergraduate students of Kerala. For comprehending this, a survey was conducted by administering questionnaires to a representative sample of 250 undergraduate students of colleges in Kerala. Stepwise Multiple Regression Analysis was carried out to analyse the data statistically to derive at valid and generalisable conclusions. The analysis revealed that Affective Environmental Sustainability Attributes significantly predicted the Green Consumer Behaviour of undergraduate students. Hence, it is imperative to embed the principles of learning for sustainability with a consumer focused approach in the curriculum for fostering Green Consumer Behaviour among the students of Higher Education. This should encompass all the domains of learning with specific emphasis on the aspects of affective environmental sustainability attributes across the disciplines paving way for a sustainable community.
\end{abstract}

Keywords: Environmental Attitudes, Environmental Values, Environmental Dispositions, Green Consumer Behaviour, Higher Education, Sustainability

\section{INTRODUCTION}

Over the years Education for Sustainability (EfS) has been focusing on nature as the embodiment of vitality acting as a life line for creatures facilitating the irreversible process of expansion. Nature harbours the reason for the existence and non-existence of the variegated Diasporas of living organisms. However, the benevolence of nature has been exploited and exhausted by humans throughout the years for their survival, and the damage inflicted upon it is colossal and exasperating. The consumption of resources for satisfying the needs and wants of consumers is one significant part of human activity for survival and existence. But, the consumption beyond the limits and in a nonecofriendly manner has resulted in the subjugation of nature. The occurrence of natural disasters like earthquakes, landslides, flood, storms, etc. are to be taken in to account as retaliation of nature for the extensive degrading activities of human beings. Both the natural and manmade adversities ring the bells for reinventing our actions towards adopting green lifestyles. Green Consumer Behaviour which is acclaimed as pro-environmental has a significant role in promoting environmental consciousness by enabling to reduce the ecological footprints of consumers for advocating sustainability. Education with a consumer focused approach to sustainability has a high potential for developing the desired behavioural change with longevity effect on the individual. This should aim for developing better cognizance that enriches all the domains of learning encompassing knowledge, values, dispositions, skills and behaviours that are pro-environmental for heeding sustainability. Education capable of producing environmentally responsible citizens who can significantly contribute their part towards restoration of nature is the need of the hour. Education aiming such transformations must build a generation sensitized with environmental issues and capacitated with adequate skills, knowledge and attitudes for manifesting environmentally responsible behaviours.

Environmental sustainability implies the capacity to maintain the qualities of the myriad elements persisting in the environment (Sutton, 2004). Education as a medium for transformation and social changes should sensitize the minds of students to the fragile state of nature owing to human activities that poses the essentiality of adopting sustainable lifestyles. HE has a significant responsibility for sustainability owing to the immense influence it has on the society and autonomy of functionality (IAU, 2006; Sherren, 2006). Education at undergraduate level with a consumer focused approach to sustainability must cater to maintain the quality of environment by sensitizing and reorienting students' actions in sustainable ways for moulding environmentally responsible citizens. Moreover, undergraduate students as educated citizens of the society too have a prominent role in inducing and influencing fellow citizens to act in an environmentally responsible manner by acting as a sensible and rational green consumer for the welfare of humanity and nation at large. One step towards education for sustainability (EfS) is by educating learners to go green and adopt sustainable lifestyles to 
uphold environmental citizenship. But several questions arise as to how far the HE has been able to develop the desired qualities in learners for orienting their actions towards building a sustainable society?

A comprehensive education has to encompass the development of all the domains of learning. This paper intends to examine how far the higher education experiences have transformed the students with specific focus on the influence of affective environmental sustainability attributes like Environmental Attitudes, Environmental Values and Environmental Dispositions on the Green Consumer Behaviour of undergraduate students. The insights gained would be beneficial to various stakeholders of education like educators, policy makers, curriculum developers, administrators etc as well as other fields like business, marketing, economics, etc. Moreover, in a country like India, where the youth forms a major part of consumer population, insights on Green Consumer Behaviour of youth would have a greater potential to contribute immensely towards building a sustainable community. Owing to the fact that each and every intricate decision of students as consumers will have a significant impact on the society, environment and fellow beings, it is imperative to comprehend the affective sustainability aspects of college students and appraise how far it has influenced in fostering their Green Consumer Behaviour.

\section{Need and Significance of the Study}

Education is the only force that can awaken the human sensibilities inorder to protect nature for living in a healthy environment. Higher education in particular has an imperative role for reorienting human actions on nature. It would indeed be highly appreciable contribution if the $\mathrm{HE}$ endeavours are able to produce graduates adorned with adequate knowledge, skills and values immensely capacitated to contribute towards the progress of the society (Chalkley, 2006). Learning is the most appropriate process whereby individuals can perceive and make sense of things happening around them (Marton \& Booth, 1997). In the process of teaching and learning the main focus must be on developing the affective attributes like values, attitudes and dispositions that invariably mediate between knowledge and behaviour (Shephard, 2008). The HE experiences of learners that are tinted with the hues of sustainability with specific focus on green consumption must play a unique role in fostering Green Consumer Behaviour among the students. As nature sustains future generations, students have a crucial role in supporting it through their enhancing consumer behaviour. When students are informed about the need for consumer behaviour, the awareness of the young minds become an un-seizing force that rejuvenates and restore nature. Then the behaviour and mode of consumption are modified and decoded for the balance of life. Due to the reinforcement of harmony and expansion of life by thoughtful acts of the students, the ecosystem regains its eco-balance. Sustainable consumers reorient the transformational process of nature. This calls for developing good conscience for bringing about a drastic change in the mindset of students as potential consumers by making them more sensible in their actions and choices.

Higher Education must be at the fore front in developing strategies for imparting sustainability in all facets of its functioning including teaching and learning. However, educators in the $\mathrm{HE}$ sector mostly focus developing the cognitive aspects of learning rather than the affective outcomes (Shephard, 2008). In addition to this, it is also to be considered that undergraduate students who are at their formative stage of education should be given ample opportunities for coming up with creative ideas for solving the problems of sustainability (Sibbel, 2009). This can be made fruitful only through the enrichment of their thoughts and actions through effective education. This would pave way for transforming students with life oriented education instilling in them the skills required for leading a successful life. The skills, knowledge and attitude required for reorganising lives intelligently for meeting the needs and wants through green consumption, which is a form of sustainable lifestyle, is becoming a buzz word now-a-days. Being a green consumer is a way of acknowledging the environmental stewardship by individuals with action oriented ecofriendly behaviours. For materialising this, the major aspects of curricula must be framed in congruence with meeting the immediate and far reaching needs of the society. Such an education must shape the young consumers of the nation to be more sensible by envisioning planetary responsibility of optimising human actions and by living in harmony with the nature.

The educators around the globe opined that, the teaching and learning in $\mathrm{HE}$ have most commonly been centred around the development of cognitive aspects of the learner, with least efforts put on identifying and designing the affective aspects of student learning. Though they are not explicitly stated, learning for affective domain nourishment is pervasive in education (Miller, 2005). Again the question arises as to how far the teaching learning pursuits have succeeded in building models and designs that are realistic and acceptable encompassing the outcomes in the affective domain? Are the students able to value the aspects and develop right attitudes and dispositions from what they learn from the institutions? To be precise, education for sustainability must rightly be a quest for affective learning outcomes. As it is really important to develop right attitudes, values and dispositions for fostering action oriented behaviours, Higher Education must incorporate sustainability aspects in all facets of educational experiences.

\section{OBJECTIVES}

The objectives of the study are as follows

1. To estimate the relative efficiency of predictor variables like Environmental Attitudes, Environmental Values and Environmental Dispositions in predicting the criterion variable Green Consumer Behaviour for the total sample. 
2. To find out the multiple correlations between the predictor variables like Environmental Attitudes, Environmental Values, Environmental Dispositions and the criterion variable Green Consumer Behaviour for the total sample.

3. To find out the significant predictors of the criterion variable Green Consumer Behaviour for the total sample.

4. To find out the relative efficiency of the significant predictor variables like Environmental Attitudes, Environmental Values and Environmental Dispositions in predicting the criterion variable Green Consumer Behaviour for the total sample.

\section{HYPOTHESES}

1. There is no significant relationship between the predictor variables like Environmental Attitudes, Environmental Values, Environmental Dispositions and the criterion variable Green Consumer Behaviour for the total sample.

2. The relative efficiency of predictor variables' individual and collective contribution is not significant in predicting the Green Consumer Behaviour for the total sample.

3. There is no significant multiple correlations between the predictor variables like Environmental Attitudes, Environmental Values and Environmental Dispositions and criterion variable Green Consumer Behaviour for the total sample.

4. The criterion variable Green Consumer Behaviour cannot be predicted from one or more of the predictor variables for the total sample.

5. The relative efficiency of the predictor variables like Environmental Attitudes, Environmental Values and Environmental Dispositions in predicting the criterion variable Green Consumer Behaviour is not different for the total sample.

\section{METHODOLOGY}

The method adopted for the study is given below.

Sample: The population of the study constitute undergraduate students attending Degree courses in the aided and government colleges of Kerala, a southernmost state in the Indian subcontinent. For the present study, a representative sample was selected from the population which consisted of 250 undergraduate students attending B.Com Degree course in aided and government colleges of Kerala.

Tool: A self-reported inventory was used to measure the Affective Sustainability Attributes with dimensions Environmental Attitudes, Environmental Values and Environmental Dispositions. The Environmental Attitudes were measured by adopting the Environmental Attitudes Inventory (EAI) developed by Milfont \& Duckitt (2010). The responses of the EAI were rated on a 7 point Likert scale ranging from Strongly Agree (7) to Strongly Disagree (1). The dimension Environmental values was measured by adopting The Brief Inventory of Values which is a scale developed by Stern, Dietz and Guagnano (1998). The dimension Environmental Dispositions was measured by adopting the Environmental Response Inventory developed by McKecnie (1970). To assess the Green Consumer Behaviour of undergraduate students, a Scale was developed and used by the investigators. The scores of Green Consumer Behaviour were rated as Always, Often, Rarely, Sometimes and Never with positive statements scored as 5, 4, 3, 2 and 1 and reverse scoring for negative items.

Statistical Techniques: The collected data was statistically analysed to derive at valid generalisable conclusions. SPSS 20 which is a statistical Package for Social Sciences was used for analysing the data. The following statistical techniques were used for analysing data:

1. Basic Descriptive Statistics (Mean, Median, Mode, Standard Deviation, Skewness, Kurtosis).

2. Stepwise Multiple Regression Analysis

\section{ANALYSIS AND INTERPRETATION}

Inorder to examine the nature of data, a preliminary analysis was conducted. This constituted computation of the important statistical constants like mean (M), median, mode, Standard Deviation (SD), skewness and kurtosis. Table 1 shows the statistical constants of the variable Ecoliteracy for the total sample.

TABLE I STATISTICAL CONSTANTS OF ECOLITERACY FOR THE TOTAL SAMPLE

\begin{tabular}{|l|c|c|c|c|c|c|c|}
\hline \multicolumn{1}{|c|}{ Variable } & No. & Mean & Median & Mode & SD & Skewness & Kurtosis \\
\hline Environmental Attitudes & 250 & 58 & 59 & 60 & 7 & .111 & -.666 \\
\hline Environmental Values & 250 & 58 & 58 & 52 & 6 & .478 & -.739 \\
\hline Environmental Dispositions & 250 & 62 & 62 & 60 & 6 & -.023 & -.650 \\
\hline Green Consumer Behaviour & 250 & 62 & 61 & 60 & 6 & .707 & .459 \\
\hline
\end{tabular}

Table I reveals that the mean, median and mode of Environmental Attitudes, Environmental Values, Environmental Dispositions and Green Consumer Behaviour for the total sample are almost equal. The standard deviation value that indicates the spread of scores above and below the mean is not large for Environmental Attitudes(7), Environmental Values (6), Environmental Dispositions (6) and Green Consumer behaviour (6). The standard deviation values indicate that the data are clustered closely around the mean. The skewness which indicates the 
measure of asymmetry is .111 for Environmental Attitudes, which shows that the distribution is positively skewed. In the case of Environmental Values, the value of skewness is .478 which shows that the distribution is also positively skewed. The skewness value of Environmental Dispositions -.023 indicates that the distribution is slightly negatively skewed. The value .707 for Green Consumer Behaviour shows that the distribution is positively skewed. The value of kurtosis -.666, -.739 and -.650 shows that the distribution is platykurtic for the predictor variables. In the case of Green Consumer Behaviour, the kurtosis value is .459, which shows that the distribution is leptokurtic. From the descriptive statistic values, it can be inferred that the distribution is approximately normal.

\section{A. Stepwise Multiple Regression Analysis}

A Stepwise Multiple Regression Analysis was done to estimate the relative efficiency of the predictor variables like Environmental Attitudes, Environmental Values and Environmental Dispositions in effectively predicting the criterion variable Green Consumer Behaviour of undergraduate students. The analysis was done to find out the individual and joint contributions of predictors in effectively predicting the criterion variable for the total sample of students. The following section gives a detailed description of the Stepwise Multiple regression Analysis.

\section{B. Relative Efficiency of Predictor Variables in Predicting the Criterion Variable for the Total Sample}

The details of analysis pertaining to estimating the relative efficiency of Environmental Attitudes, Environmental Values and Environmental Dispositions in effectively predicting the Green Consumer Behaviour of Students are described in this section. Table 2 presents the inter correlation matrix between the predictors and the criterion variable for total sample.

\section{TABLE II PEARSON'S CORRELATION MATRIX OF PREDICTORS AND CRITERION VARIABLE FOR THE TOTAL SAMPLE}

\begin{tabular}{|l|c|c|c|c|}
\hline \multicolumn{1}{|c|}{ Variables } & $\begin{array}{c}\text { Environmental } \\
\text { Attitudes }\end{array}$ & $\begin{array}{c}\text { Environmental } \\
\text { Values }\end{array}$ & $\begin{array}{c}\text { Environmental } \\
\text { Dispositions }\end{array}$ & $\begin{array}{c}\text { Green Consumer } \\
\text { Behaviour }\end{array}$ \\
\hline $\begin{array}{l}\text { Environmental } \\
\text { Attitudes }\end{array}$ & 1 & & & \\
\hline $\begin{array}{l}\text { Environmental } \\
\text { Values }\end{array}$ & $.479^{* *}$ & 1 & 1 & \\
\hline $\begin{array}{l}\text { Environmental } \\
\text { Dispositions }\end{array}$ & $.479^{* *}$ & $.518^{* *}$ & $.635^{* *}$ & 1 \\
\hline $\begin{array}{l}\text { Green Consumer } \\
\text { Behaviour }\end{array}$ & $.640^{* *}$ & $.632^{* *}$ & ${ }^{* *}$ Correlation is Significant at .01 levels (2-tailed) \\
\hline
\end{tabular}

Table II reveal that there exists significant positive correlation among the predictor variables Environmental Attitudes, Environmental Values and Environmental Dispositions and the criterion variable Green Consumer Behaviour for the total sample. It can be seen that Environmental Attitudes $\left(\mathrm{r}=.640,{ }^{* *} p<.01\right)$ is having the highest correlation with the criterion variable followed by Environmental Dispositions $\left(\mathrm{r}=.635,{ }^{* *} p<.01\right)$ and thirdly Environmental Values $\left(\mathrm{r}=.632,{ }^{* *} p<.01\right)$. From the table it is evident that all the correlation indices are significant at .01 levels.

A Stepwise Multiple Regression Analysis was done to find out the relative efficiency of the predictors in predicting the criterion variable for the total sample. The model summary of Stepwise Multiple Regression Analysis with the factors of Green Consumer Behaviour consisting of Environmental Attitudes, Environmental Values and Environmental Dispositions for the total sample is presented in Table III.

TABLE III REGRESSION MODEL SUMMARY OF GREEN CONSUMER BEHAVIOUR ${ }^{\mathrm{D}}$ FOR THE TOTAL SAMPLE

\begin{tabular}{|c|c|c|c|c|}
\hline Model & R & R Square & $\begin{array}{c}\text { Adjusted } \\
\text { R Square }\end{array}$ & $\begin{array}{c}\text { R Square } \\
\text { Change }\end{array}$ \\
\hline 1 & $.640^{\mathrm{a}}$ & .409 & .407 & .409 \\
\hline 2 & $.741^{\mathrm{b}}$ & .549 & .546 & .140 \\
\hline 3 & $.782^{\mathrm{c}}$ & .611 & .607 & .062 \\
\hline
\end{tabular}

a. Predictors: (Constant), Environmental Attitudes b. Predictors: (Constant), Environmental Attitudes, Environmental Dispositions c. Predictors: (Constant), Environmental Attitudes, Environmental Dispositions, Environmental Values d. Dependent Variable: Green Consumer Behaviour

Table III shows that for Model 1, the correlation $(\mathrm{R}=.640)$ between the predictor Environmental Attitudes and the criterion Green Consumer Behaviour shows a positive correlation. The coefficient of determination ( $\mathrm{R}=.409)$ shows that $41 \%$ of the variance of the criterion variable has been significantly explained by the predictor variable. The Adjusted R Square $(\mathrm{R}=.407)$ determines how well the model can be generalised.

In the case of Model 2, the multiple correlations between the predictors (Environmental Attitudes and Environmental Values) and the criterion Green Consumer Behaviour $(\mathrm{R}=.741)$ shows a relatively strong positive correlation. The coefficient of determination .549 shows that $55 \%$ of the variance of the criterion variable has been significantly explained by the predictor variables. The percentage increase in variance depicted (.140) is 14\%. The Adjusted R Square value of .546 shows that $55 \%$ of the variance in the predictor variables is accounted for if the model has been derived from the population from which the sample was taken. 
Further, Model 3 shows that multiple correlations between the predictors (Environmental Attitudes and Environmental Values) and the criterion Green Consumer Behaviour $(\mathrm{R}=.782)$ show a relatively strong positive correlation. The coefficient of determination $\mathrm{R}^{2}$ is .61 which shows that $61 \%$ of the variance of the criterion variable has been significantly explained by the predictor variables jointly. The percentage increase in variance (.062) is 6\%. The
Adjusted R Square value of .607 shows that $61 \%$ of the variance in the predictor variables is accounted for if the model has been derived from the population from which the sample was taken.

The ANOVA in regression analysis is presented in Table IV.

TABLE IV ANALYSIS OF VARIANCE ${ }^{\text {A }}$ IN REGRESSION ANALYSIS

\begin{tabular}{|c|l|c|c|c|c|c|}
\hline S. No. & \multicolumn{1}{|c|}{ Model } & Sum of Squares & df & Mean Square & F & Sig. \\
\hline \multirow{3}{*}{1} & Regression & 3666.861 & 1 & 3666.861 & & $.000^{\mathrm{b}}$ \\
& Residual & 5290.435 & 248 & 21.332 & 171.892 & \\
& Total & 8957.296 & 249 & & & \\
\hline \multirow{3}{*}{2} & Regression & 4921.215 & 2 & 2460.608 & & $.000^{\mathrm{c}}$ \\
& Residual & 4036.081 & 247 & 16.340 & 150.584 & \\
& Total & 8957.296 & 249 & & & \\
\hline \multirow{6}{*}{3} & Regression & 5476.862 & 3 & 1825.621 & & $.000^{\mathrm{d}}$ \\
& Residual & 3480.434 & 246 & 14.148 & 129.036 & \\
& Total & 8957.296 & 249 & & & \\
\hline
\end{tabular}

From Table IV it can be seen that for Model 1, the F $(1,248)$ $=171.892,{ }^{* *} p<.01$ is greater than the table value for corresponding degrees of freedom at .01 level. The table value of $F(1,248)=6.69, \stackrel{* *}{p} p<.01$ is significant at .01 level. This means that Environmental Attitudes significantly predict Green Consumer Behaviour of students for the total sample.

For Model 2, the F value 150.584 is greater than the table value for corresponding degrees of freedom at .01 level. The table value of $F(2,247)=4.65,{ }^{* *} p<.01$ is significant at .01 level. This means that Environmental Attitudes and Environmental Dispositions significantly predict Green Consumer Behaviour of students for the total sample.
For Model 3, the $\mathrm{F}(3,246)=129.036,{ }^{* *} p<.01$ is greater than the table value for corresponding degrees of freedom at .01 level. The table value of $\mathrm{F}(3,246)=3.82,{ }^{* *} p<.01$ is significant at .01 level. This means that Environmental Attitudes, Environmental Dispositions and Environmental Values significantly predict Green Consumer Behaviour of students for the total sample.

Table $\mathrm{V}$ shows the regression coefficients related to the individual contribution of predictors in predicting the criterion variable for the total sample.

TABLE V REGRESSION COEFFICIENTS ${ }^{A}$ OF PREDICTORS WITH RESPECT TO INDIVIDUAL CONTRIBUTION IN PREDICTING THE CRITERION VARIABLE FOR THE TOTAL SAMPLE

\begin{tabular}{|c|c|c|c|c|c|c|}
\hline \multirow{2}{*}{ S. No. } & \multirow{2}{*}{ Model } & \multicolumn{2}{|c|}{$\begin{array}{c}\text { Unstandardized } \\
\text { Coefficients }\end{array}$} & \multirow{2}{*}{$\begin{array}{c}\text { Standardized } \\
\text { Coefficients }\end{array}$} & \multirow[t]{2}{*}{$\mathbf{t}$} & \multirow{2}{*}{ Sig. } \\
\hline & & $\mathbf{B}$ & Std. Error & & & \\
\hline \multirow[b]{2}{*}{1} & (Constant) & 30.626 & 2.419 & & 12.662 & .000 \\
\hline & Environmental Attitudes & .540 & .041 & .640 & 13.111 & .000 \\
\hline \multirow{3}{*}{2} & (Constant) & 13.204 & 2.904 & & 4.546 & .000 \\
\hline & Environmental Attitudes & .368 & .041 & .435 & 8.948 & .000 \\
\hline & Environmental Dispositions & .445 & .051 & .426 & 8.762 & .000 \\
\hline & (Constant) & 7.513 & 2.851 & & 2.635 & .009 \\
\hline & Environmental Attitudes & .290 & .040 & .344 & 7.226 & .000 \\
\hline & Environmental Dispositions & .326 & .051 & .312 & 6.381 & .000 \\
\hline & Environmental Values & .301 & .048 & .306 & 6.267 & .000 \\
\hline
\end{tabular}


From Table $\mathrm{V}$ it is clear that for Model 1, Beta value (B) is .640 which represents the estimated change in criterion variable with one standard deviation change in predictor variable. The $\mathrm{B}$ value. 540 represents the change in criterion variable associated with a unit change in the predictor variable. The constant 30.626 relates to the amount of criterion variable without the contribution of predictor variable. Thus, for Model 1, if Environmental Attitudes is increased by one unit, the model predicts .540 units increase in Green Consumer Behaviour. For this model Environmental Attitudes, $\mathrm{t}=13.111,{ }^{* *} p<.01$ is a significant predictor of Green Consumer Behaviour. Hence, it can be inferred that the individual contribution of Environmental Attitudes is significant in predicting the Green Consumer behaviour of students for the total sample.

\section{Multiple Regression Equation for Model 1}

The B value of Environmental Attitudes is .540 and the standard error is .041. The regression equation for predicting Green Consumer Behaviour (Y) by Environmental Attitude $\left(X_{1}\right)$ of general form $Y=\beta_{0}+\beta_{1} X_{1}+$ $\beta_{2} X_{2}+\ldots \ldots \ldots \ldots \ldots+\beta_{n} X_{n}+\varepsilon t$ is given below.

Green Consumer Behaviour $=\beta_{0}+\beta_{1}$ Environmental Attitudes $+\varepsilon t$

Green Consumer Behaviour $=30.626+.540$ Environmental Attitudes

According to this equation, for unit increase in Environmental Attitudes $\left(\mathrm{X}_{1}\right)$, Green Consumer Behaviour (Y) increases by .540 units.

From Table V it is clear that for Model 2, Beta values (ß) of Environmental Attitudes and Environmental Dispositions are .435 and .426 respectively which represents the estimated change in criterion variable with one standard deviation change in predictor variable. The B values of Environmental Attitudes and Environmental Dispositions are .368 and .445 respectively which represents the change in criterion variable associated with a unit change in the predictor variable. The constant 13.204 relates to the amount of criterion variable without the contribution of predictor variable. For this model Environmental Attitudes, $\mathrm{t}=8.948, \quad{ }^{* *} p<.01$ and Environmental Dispositions, $\mathrm{t}=$ $8.762, \stackrel{* *}{*} p<.01$ are significant at .01 level. Hence, it can be inferred that the joint contribution of Environmental Attitudes and Environmental Dispositions is significant in predicting the Green Consumer behaviour of students.

\section{Multiple Regression Equation for Model 2}

The B values of Environmental Attitudes and Environmental Dispositions are .368 and .445 with standard errors .041 and .051 respectively. The regression equation for predicting Green Consumer Behaviour (Y) by Environmental Attitudes $\left(\mathrm{X}_{1}\right)$ and Environmental Dispositions $\left(X_{2}\right)$ of general form $Y=\beta_{0}+\beta_{1} X_{1}+\beta_{2} X_{2}$ $+\ldots \ldots \ldots \ldots \ldots+\beta_{n} X_{n}+\varepsilon t$ is given below.
Green Consumer Behaviour $=\beta_{0}+\beta_{1}$ Environmental Attitudes $+\beta_{2}$ Environmental Dispositions $+\varepsilon t$

Green Consumer Behaviour $=13.204+.368$ Environmental Attitudes +.445 Environmental Dispositions

According to this equation, for unit increase in Environmental Attitudes $\left(\mathrm{X}_{1}\right)$, Green Consumer Behaviour (Y) increases by .368 units when the effect of Environmental Dispositions $\left(\mathrm{X}_{2}\right)$ is held constant. Similarly, for unit increase in Environmental Dispositions $\left(\mathrm{X}_{2}\right)$, Green Consumer behaviour ( $\mathrm{Y}$ ) increases by .445 units provided the effects of Environmental Attitudes $\left(\mathrm{X}_{1}\right)$ is held constant.

From Table 5 it is evident that for Model 3, Beta values (B) of Environmental Attitudes, Environmental Dispositions and Environmental Values are .344, .312 and .306 respectively which represents the estimated change in criterion variable with one standard deviation change in predictor variable. The $\mathrm{B}$ values of Environmental Attitudes, Environmental Dispositions and Environmental Values are .290, .326 and .301respectively which represent the change in criterion variable associated with a unit change in the predictor variable. The constant 7.513 relates to the amount of criterion variable without the contribution of predictor variable. For this model Environmental Attitudes, $\mathrm{t}=7.226,{ }^{* *} p<.01$, Environmental Dispositions, $\mathrm{t}$ $=6.381,{ }^{* *} p<.01$ and Environmental Values, $\mathrm{t}=6.267$, ${ }^{* *} p<.01$ are significant at .01 level. Hence, it can be inferred that the joint contribution of predictors is significant in predicting the Green Consumer behaviour of students.

\section{E. Multiple Regression Equation for Model 3}

The B values of Environmental Attitudes, Environmental Dispositions and Environmental Values are .290, .326 and .301 respectively with standard errors .040, .051 and .048 respectively. The regression equation for predicting Green Consumer Behaviour (Y) by Environmental Attitudes $\left(\mathrm{X}_{1}\right)$, Environmental Dispositions $\left(\mathrm{X}_{2}\right)$ and Environmental Values $\left(X_{3}\right)$ of general form $Y=\beta_{0}+\beta_{1} X_{1}+\beta_{2} X_{2}+\ldots \ldots \ldots \ldots \ldots .+$ $B_{n} X_{n}+\varepsilon t$ is given below.

Green Consumer Behaviour $=\beta_{0}+\beta_{1}$ Environmental Attitudes $+\beta_{2}$ Environmental Dispositions + $\beta_{3}$ Environmental Values $+\varepsilon t$

Green Consumer Behaviour $=7.513+.290$ Environmental Attitudes+ .326Environmental Dispositions + .301Environmental Values

According to this equation, for unit increase in Environmental Attitudes $\left(\mathrm{X}_{1}\right)$, Green Consumer Behaviour (Y) increases by .290 units when the effect of Environmental Dispositions $\left(\mathrm{X}_{2}\right)$ and Environmental Values $\left(X_{3}\right)$ are held constant. Similarly, for unit increase in Environmental Dispositions $\left(\mathrm{X}_{2}\right)$, Green Consumer behaviour (Y) increases by .326 units provided the effects of Environmental Attitudes $\left(\mathrm{X}_{1}\right)$ and Environmental Values $\left(\mathrm{X}_{3}\right)$ are held constant. Likewise, for unit increase in Environmental Values $\left(\mathrm{X}_{3}\right)$, Green Consumer behaviour (Y) increases by .301 units provided the effects of 
Environmental Attitudes $\left(\mathrm{X}_{1}\right)$ and Environmental Dispositions $\left(\mathrm{X}_{2}\right)$ are held constant.

\section{DISCUSSION AND CONCLUSION}

Significant correlation was found among the predictors Environmental Attitudes, Environmental Values and Environmental Dispositions and Criterion Variable Green Consumer Behaviour for the total student sample. A significant regression equation was derived for Model $1, \mathrm{~F}$ $(1,246)=171.892,{ }^{* * *} p<.01$, with $\mathrm{R}^{2}=.41$.The regression equation for the first model was Green Consumer Behaviour $(\mathrm{Y})=30.626+.540$ Environmental Attitudes. A significant regression equation was derived for Model 2, F $(2,247)=$ $150.584, \stackrel{* *}{p}<<.01$, with $\mathrm{R}^{2}=.55$. The regression equation for the second model was Green Consumer Behaviour $(\mathrm{Y})=$ $13.204+.368$ Environmental Attitudes +.445 Environmental Dispositions. A significant regression equation $\left(\mathrm{F}(3,246)=129.036,{ }^{* *} p<.01\right)$, with an $\mathrm{R}^{2}$ of .61 was yielded. This shows that Environmental Attitudes, Environmental Dispositions and Environmental Values collectively accounts for $61 \%$ variation in GCB of undergraduate students. Participants' GCB is equal to 7.513 +.290 Environmental Attitudes + .326 Environmental Dispositions +.301 Environmental Values.

The findings derived from the study lead the authors to propose the following aspects which are having wider implications both at the theoretical and practical aspects of education. The educational pursuits seeking sustainability in HE must exceptionally be diverse by infusing green behaviour either at institutional or individual levels through the teaching - learning process in a micro and macro manner. The institutional level transformations must involve adopting policies and practices of energy conservation, recycling, adopting green infrastructure, manifesting green purchase behaviour, etc at functional level. The subject of environment may be either taught as a separate discipline or be infused in the curriculum and taught through different subjects in a multidisciplinary and trans-disciplinary manner. Such HE endeavours must be able to attain the predefined objectives of education for sustainability. The students of HE must be able to imbibe such sustainability qualities, specifically the Green Behaviour from the institutional experiences from within and outside the walls of their classrooms. The teaching and learning at HE level must be comprehensive enough in developing all the domains of learning like cognitive, affective and psychomotor aspects in education for sustainability. Above all the students must be empowered with adequate knowledge, skills and attitude for manifesting environmentally responsible behaviours for upholding planetary citizenship.
Higher education can contribute green prodigies for the society. They retain the hues and flavours of nature without disturbing its core. The longevity of sustainable consumption depends upon the depth of knowledge relating to sustainable behaviour. When the foe in humans extends a cordial hand to nature, it unassumingly turns into a cradle of simmering life. The sense of duty towards nature has a resonating effect on its sustainability. Mere human existence cannot incorporate awareness. It must be imparted systematically from the very beginning of schooling. Green Consumer Behaviour must play out more as a habit in a student. The young minds are to be framed for an understanding of the exclusive role of nature in supporting the system of life by providing the platform for enhancing Green Consumer Behaviour skills; higher education sector brings sweeping progress in all walks of human life. It revamps human existence and programmes the encoding of each and every life system embedded in nature.

\section{REFERENCES}

[1] B. Chalkley, "Education for sustainable development: Continuation", Journal of Geography in Higher Education, Vol. 30, No. 2, pp. 235236, 2006.

[2] International Association of Universities, "IAU Conference: Education for a Sustainable Future. Conference General Report", 2006. Retrieved from: www.unesco.org/iau/sd/sd_confprague.html.

[3] F. Marton, and S. A. Booth, "Learning and awareness", Psychology Press, 1997.

[4] G. E. McKechnie, "Measuring environmental dispositions with the environmental response inventory", 1970. Retrieved from: http://citeseerx.ist.psu.edu/viewdoc/download?doi $=10.1 .1 .452 .7746 \&$ rep $=$ rep $1 \&$ type $=p d f$

[5] T. L. Milfont, J. Duckitt and C. Wagner, "The higher order structure of environmental attitudes: A cross-cultural examination", Interamerican Journal of Psychology, Vol. 44, No. 2, 2010.

[6] M. Miller, "Learning and teaching in the affective domain", In Orey, M. (Ed.), "Emerging Perspectives on Learning, Teaching and Technology", College of Education eBook University of Georgia, Athens, 2005.

[7] K. Shephard, "Higher education for sustainability: seeking affective learning outcomes", International Journal of Sustainability in Higher Education, Vol. 9, No. 1, pp. 87-98, 2008.

[8] K. Sherren, "Core issues: reflections on sustainability in Australian University coursework programs", International Journal of Sustainability in Higher Education, Vol. 7, No. 4, pp. 400-13, 2006.

[9] Sibbel, "Pathways towards sustainability through higher education", International Journal of Sustainability in Higher Education, Vol. 10, No. 1, pp. 68-82, 2009.

[10] P. C. Stern, T. Dietz, T. Abel, G. A. Guagnano and L. Kalof, "A value-belief-norm theory of support for social movements: The case of environmentalism", Human ecology review, pp. 81-97, 1999.

[11] P. C. Stern, T. Dietz and G. A. Guagnano, "A brief inventory of values", Educational and Psychological Measurement, Vol. 58, No. 6, pp. 984-1001, 1998.

[12] P. Sutton, "A perspective on environmental sustainability", Paper on the Victorian Commissioner for Environmental Sustainability, pp. 132, 2004. 